\title{
Analysis of the Government Health Expenditure in the First Decade of Chinese New Medical Reform (2009-2018): Xinjiang Uygur Autonomous Region as an Example
}

This article was published in the following Dove Press journal:

Risk Management and Healthcare Policy

\author{
Chun-yang Feng' \\ Ruo-hao Liang ${ }^{2}$ \\ Xi-ming Jiang ${ }^{2}$ \\ 'Treasury Department, Urumqi Central \\ Sub-Branch of the People's Bank of China, \\ Urumqi, Xinjiang, People's Republic of \\ China; ${ }^{2}$ Accounting College, Xinjiang \\ University of Finance \& Economics, \\ Urumqi, Xinjiang, People's Republic of \\ China
}

\begin{abstract}
Objective: To analyze the status of government health expenditure in Xinjiang Uygur Autonomous Region since the first 10 years from the new medical reform, and find the existing problems in order to provide evidence for the government to formulate medical and health policies. Methods: Based on the health expenditure monitoring data of Xinjiang Uygur Autonomous Region government from Urumqi Central Sub-branch of the People's Bank of China, combined with the relevant data in Xinjiang statistical yearbook, Excel2013 and SPSS19.0 were used to conduct a comparative analysis of government expenditure data from 2009 to 2018.
\end{abstract}

Results: The average annual growth rate of the government's health expenditure in Xinjiang Uygur Autonomous Region was $12.25 \%$, which was similar to the national level. The proportion of government health expenditure in gross domestic product increased from $0.97 \%$ to $1.07 \%$, while the proportion in the total fiscal expenditure decreased from $3.06 \%$ to $2.63 \%$, which led to far behind the national and even western area level. The Gini Coefficient of per capita government health expenditure in every city (state) of the autonomous region fell from 0.46 to 0.32 between 2014 and 2018. In the past decade, the ratio between public health expenditure and medical institution expenditure has decreased from 1.01 to 0.42 , led to insufficient proportion of public health expenditure. The health expenditure level of the four prefectures especially Kashgar and Hotan in Southern Xinjiang was still far lower than the whole autonomous region and the national average level.

Conclusion: The government of Xinjiang Uygur Autonomous Region should continuously strengthen the financial expenditure in health, maintain the current situation of preferential policy implementation for rural and grassroots expenditure, constantly optimize the proportion of various financial expenditures, and strive for the transfer payment from the central and autonomous regional governments to the four prefectures in Southern Xinjiang.

Keywords: new medical reform, Xinjiang Uygur Autonomous Region, government finance, health

\section{Introduction}

Xinjiang Uygur Autonomous Region locates in the hinterland of Eurasia and the northwest frontier of China. Its total area is 1,664,900 square kilometers, accounting for about one sixth of Chinese total land area. By the end of 2018, Xinjiang had a permanent population of 24.8676 million, with GDP of 1219.9 billion Yuan (CNY).
Correspondence: Xi-ming Jiang Email xjjxm2020@I63.com 
Since the Central Committee of the Communist Party of China and the State Council issued the Opinions on Deepening the Reform of Medical and Health system in April 2009, a new round of health reforms had been started, which put forward the short-term goals of "effectively reducing the burden of medical expenses on residents, effectively easing the difficulty and high cost of medical treatment", and the long-term goals of establishing and improving the basic medical and health system covering both urban and rural residents, and providing safe, effective, convenient and inexpensive medical and health services for the people. ${ }^{1,2}$ The public welfare-oriented reform line established by the new healthcare reform plan has made it clear that government responsibility played an indispensable role in health care. ${ }^{3,4}$ However, the most immediate embodiment of government responsibility was that at all levels of Chinese government invest in the field of health care through the financial expenditure. $^{5,6}$ Furthermore, it was necessary to make a further analysis and evaluation of the government expenditure, that to assess whether the government financial health expenditure met the requirements of the medical reform and achieved the goals of the medical reform.

The Chinese new medical reform has been lasting the first 10 years by 2018 . The emphasis of this study was to suggest the current situation of the health expenditure at all levels of government in Xinjiang Uygur Autonomous Region during the past decade and analyzed the existing problems in the financial expenditure of health in Xinjiang Uygur Autonomous Region, therefore providing a certain foundation for at all levels of governments in Xinjiang Uygur Autonomous Region to formulate medical and health policies.

\section{Methods}

\section{Data Sources}

All Data based on the health expenditure monitoring data of Xinjiang Uygur Autonomous Region government from Urumqi Central Sub-branch of the People's Bank of China, combined with the relevant data about population, financial expenditure and GDP in Xinjiang Statistical Yearbook. All data in this study were open government data and therefore needed not to require the approval of the ethics committee.

\section{Statistical Caliber}

Government expenditure on health investment is the expenditure on medical and health care and family planning under the functional classification of general public budget expenditure of the classification of government revenue and expenditure (210 categories), which includes the expenditure on medical and health management, public hospitals and grass-roots medical and health institutions, public health, medical security, traditional Chinese medicine and family planning, even on the supervision and management of food and drug. However, the rehabilitation expenditure of disabled persons, the government subsidies for medical insurance of laid-off workers, the expenditure on medical insurance administration (the three categories are the 208 category of expenditure function classification of general public budget), and the expenditure on health services of the army and armed police are not included. ${ }^{7}$ The government financial expenditure on health care is also the most common database used to reflect the level and structure of health financial expenditure in China.

\section{Statistical Analysis}

Excel 2013 and SPSS 19.0 were used to conduct a comparative analysis of government expenditure data from 2009 to 2018. Gini Coefficient also was calculated by Excel 2013.

\section{Results}

\section{Overall Level of Government Health Expenditure}

As could be seen from Table 1 and Figure 1, the total health expenditure of the Xinjiang Uygur Autonomous Region Government reached 69,865,911,051 Yuan from 2009 to 2018, with an average annual growth of $12.25 \%$. For the past 10 years of the new medical reform, the government's health expenditure funds have increased from 4,125,418,263 Yuan in 2009 to 5,906,529,018 Yuan in 2011 and then dropped back to 5,524,416,907 Yuan in 2012. The funds surged to $7,147,070,976$ Yuan in 2015 after the decrease in 2013 and 2014 and then increased year by year. The average annual growth rate of per capita government health expenditure increased by $10.68 \%$, from 191.08 Yuan in 2009 to 267.38 Yuan in 2011, then dropped back to 247.40 Yuan in 2012, but it increased from 302.84 Yuan to 526.95 Yuan between 2015 and 2018. The proportion of government health care expenditure in gross domestic product (GDP) increased from $0.97 \%$ to $1.07 \%$, while the proportion of government health care expenditure in the whole financial expenditure decreased from $3.06 \%$ to $2.63 \%$. Meanwhile, the two proportions also were much lower than the levels of whole of China (Figure 2). 
Table I List of Government's Health Expenditure in Xinjiang Uygur Autonomous Region from 2009 to 2018

\begin{tabular}{|l|l|l|l|l|l|l|l|}
\hline & $\begin{array}{l}\text { Total } \\
\text { Expenditure } \\
\text { (Yuan) }\end{array}$ & $\begin{array}{l}\text { Population } \\
\text { (Ten } \\
\text { Thousands } \\
\text { People) }\end{array}$ & $\begin{array}{l}\text { Per Capital } \\
\text { Expenditure } \\
\text { (Yuan) }\end{array}$ & $\begin{array}{l}\text { GDP } \\
\text { (100 Million } \\
\text { Yuan) }\end{array}$ & $\begin{array}{l}\text { Proportion } \\
\text { of GDP } \\
\text { (\%) }\end{array}$ & $\begin{array}{l}\text { Financial } \\
\text { Expenditure } \\
\text { (100 Million } \\
\text { Yuan) }\end{array}$ & $\begin{array}{l}\text { Proportion of } \\
\text { Financial } \\
\text { Expenditure (\%) }\end{array}$ \\
\hline 2009 & $4,125,418,263$ & 2159 & 191.08 & 4273.58 & 0.97 & 1346.91 & 3.06 \\
2010 & $4,482,389,463$ & 2181 & 205.14 & 5418.81 & 0.83 & 1698.91 & 2.64 \\
2011 & $5,906,529,018$ & 2209 & 267.38 & 6474.54 & 0.91 & 2284.49 & 2.59 \\
2012 & $5,524,416,907$ & 2233 & 247.40 & 7466.32 & 0.74 & 2720.07 & 2.03 \\
2013 & $5,074,812,024$ & 2264 & 224.15 & 8360.20 & 0.61 & 3067.12 & 1.65 \\
2014 & $5,766,518,689$ & 2298 & 250.94 & 9264.10 & 0.62 & 3317.79 & 1.74 \\
2015 & $7,147,070,976$ & 2360 & 302.84 & 9324.80 & 0.77 & 3804.87 & 1.88 \\
2016 & $8,747,214,571$ & 2398 & 364.77 & 9617.23 & 0.91 & 4138.25 & 2.11 \\
2017 & $9,986,320,562$ & 2445 & 408.44 & $10,920.09$ & 0.91 & 4637.24 & 2.15 \\
2018 & $13,105,220,578$ & 2487 & 526.95 & $12,199.08$ & 1.07 & 4985.57 & 2.63 \\
\hline
\end{tabular}

Abbreviation: GDP, gross domestic product.

In addition, the Gini Coefficient of per capita government health expenditure between fourteen cities (states) of the autonomous region fell from 0.46 to 0.32 between 2014 to 2018 (Figure 3). Which meant not evenly distributed internally in 2014 and 2015, the per capita government health expenditure varied greatly in different cities (states) of Xinjiang. From 2016, per capita government health expenditure tended to average in different cities (states) of Xinjiang.

\section{Distribution of Government Health Expenditure}

Government health expenditure includes public health expenditure and medical institution expenditure. From
Tables 2 and 3 we could see, in the past 10 years, the total expenditure in public health and medical institutions was 24,897,529,507 Yuan and 44,968,381,544 Yuan respectively, while the ratio of the two decreased from 1.01 to 0.42 , that was statistically significant $\left(\chi^{2}=5.728\right.$, $P<0.01)$.

In the past 10 years, the expenditure of medical institutions has increased from 2,056,890,435 Yuan in 2009 to $9,199,085,270$ Yuan in 2018, with an average annual growth rate of $16.16 \%$. In every item of primary expenditure invested by medical institutions, the total expenditure of public hospitals reached 31,666,540,702 Yuan, and with an annual growth rate of $13.16 \%$, while the total expenditure of grassroots medical and health institutions reached

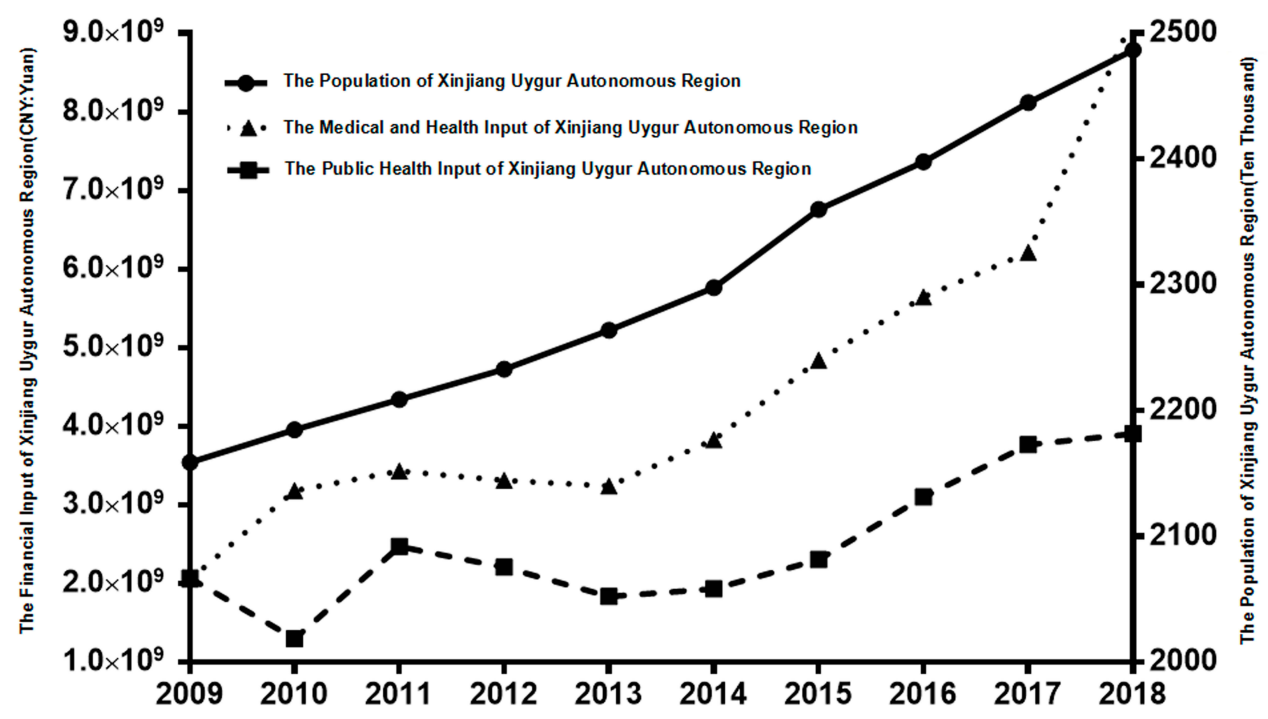

Figure I A trend chart of the relationship between Xinjiang Uygur Autonomous Region population and government health expenditure from 2009 to 2018. 


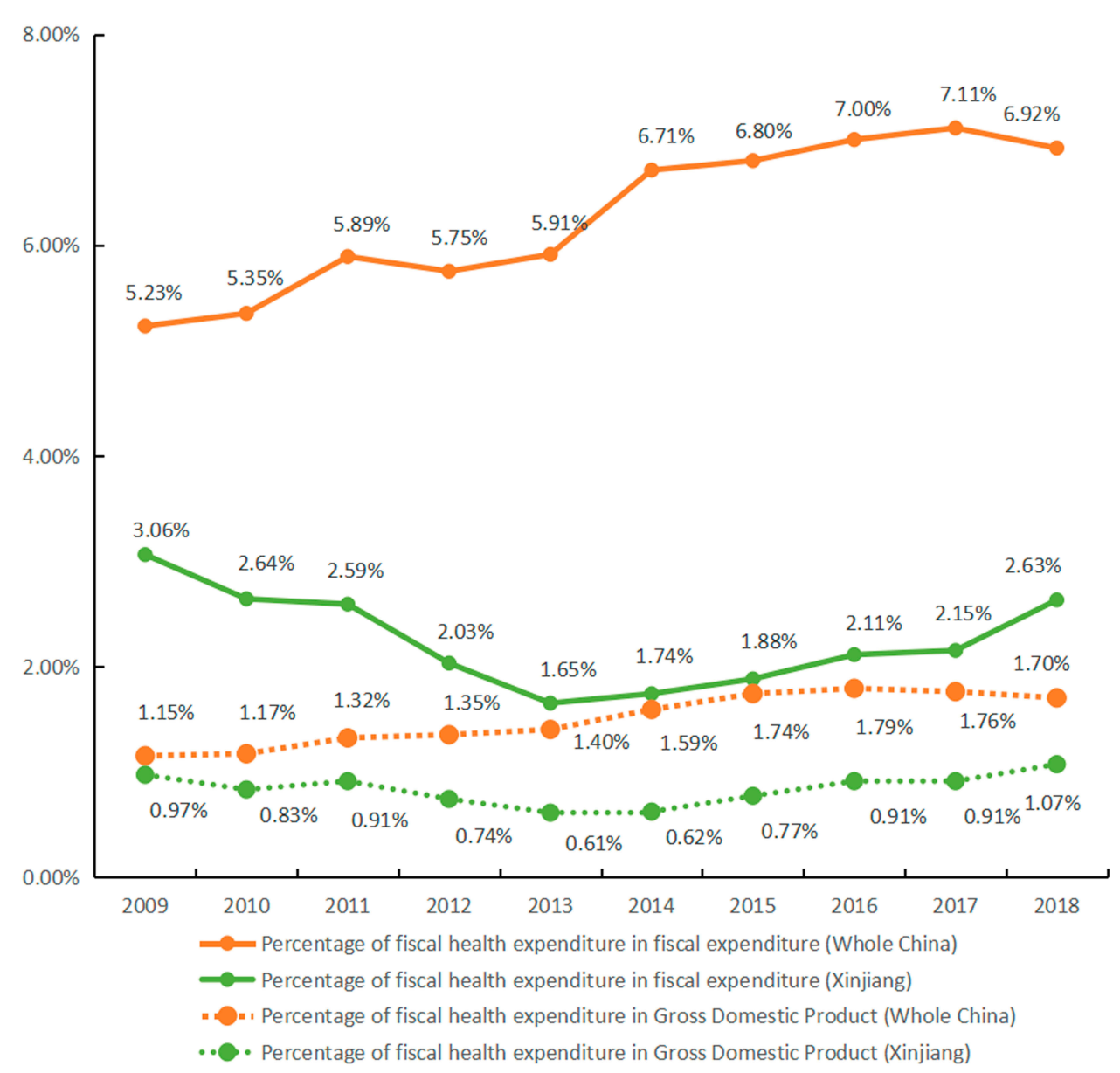

Figure 2 The proportion of fiscal health expenditure in gross domestic product (GDP) or total fiscal revenue in whole China and Xinjiang.

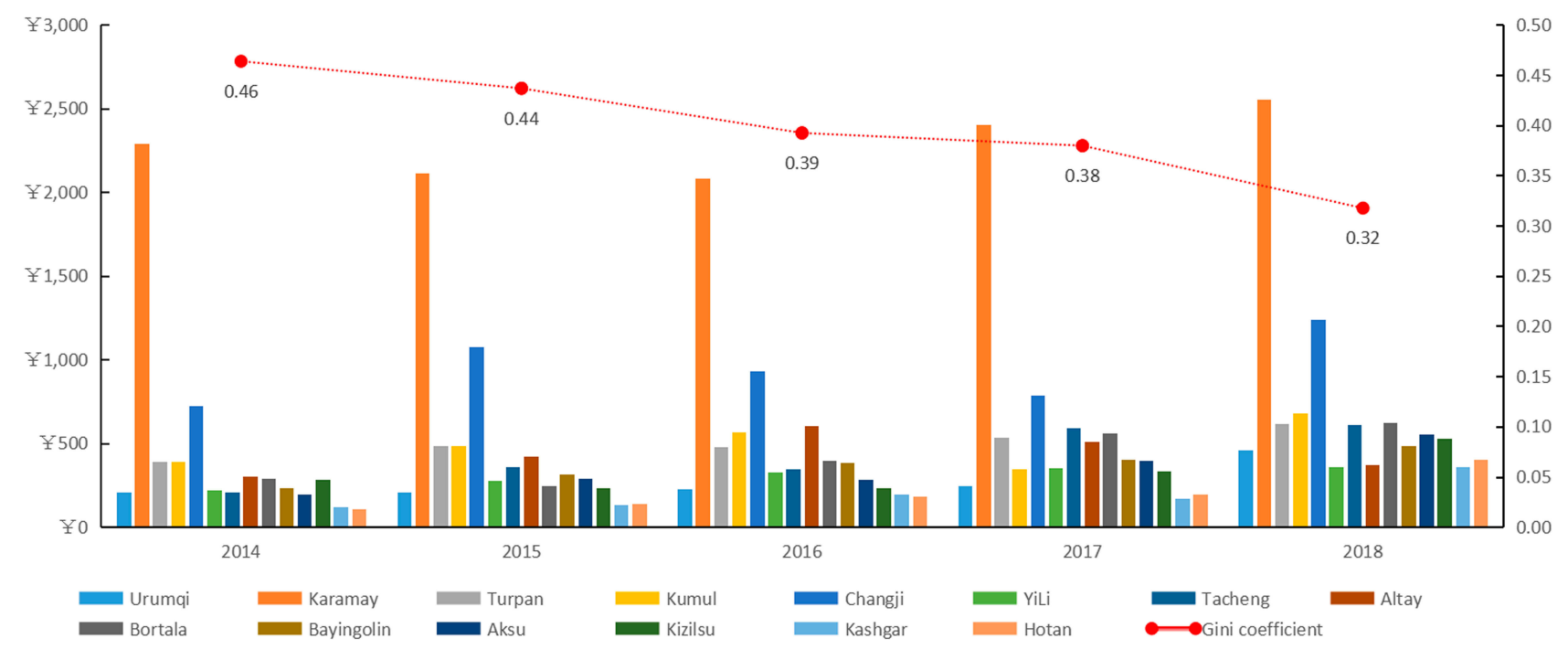

Figure 3 Gini Coefficient analysis of per capita government health expenditure between fourteen cities (states) of Xinjiang Uygur Autonomous Region. Notes: The left ordinate represents per capita health expenditure (Yuan); the right ordinate represents the Gini coefficient. 
Table 2 List of Medical Institution Expenditure of Xinjiang Uygur Autonomous Region Government from 2009 to 2018 (Yuan)

\begin{tabular}{|c|c|c|c|c|c|c|c|}
\hline & \multicolumn{3}{|c|}{ Public Hospitals } & \multicolumn{3}{|c|}{ Primary Medical and Health Institutions } & \multirow[t]{2}{*}{ Total } \\
\hline & $\begin{array}{l}\text { General } \\
\text { Hospitals }\end{array}$ & $\begin{array}{l}\text { Traditional } \\
\text { Chinese } \\
\text { Medicine } \\
\text { Hospitals }\end{array}$ & Others & $\begin{array}{l}\text { Urban } \\
\text { Community } \\
\text { Health } \\
\text { Institutions }\end{array}$ & $\begin{array}{l}\text { Township } \\
\text { Hospital }\end{array}$ & $\begin{array}{l}\text { Other basic } \\
\text { Medical and Health } \\
\text { Institutions }\end{array}$ & \\
\hline 2009 & $1,522,158,500$ & $178,5 \mid 1,767$ & $127,853,180$ & $123,169,542$ & $24,370,642$ & $80,826,804$ & $2,056,890,435$ \\
\hline 2010 & $1,899,480,165$ & $237,286,341$ & $97,867,381$ & $326,323,179$ & $312,808,545$ & $308,781,955$ & $3,182,547,566$ \\
\hline 2011 & $|, 6| 3,747,74 \mid$ & $405,174,474$ & $575,674,569$ & $200,582,94 I$ & $327,303,007$ & $312,116,790$ & $3,434,599,522$ \\
\hline 2012 & $1,695,419,648$ & $319,853,135$ & $268,093,436$ & $206,835,471$ & $583,627,042$ & $242,533,797$ & $3,316,362,529$ \\
\hline 2013 & $1,615,646,129$ & $292,260,367$ & $100,426,861$ & $235,6 \mid 4,258$ & $593,046,477$ & $403,383,643$ & $3,240,377,735$ \\
\hline 2014 & $2,087,193,864$ & $445,009,489$ & $105,508,019$ & $219,856,553$ & $628,899,196$ & $345,984,647$ & $3,832,451,768$ \\
\hline 2015 & $2,497,026,215$ & $565,733,406$ & $334,293,677$ & $236,173,708$ & $799,122,179$ & $410,130,244$ & $4,842,479,429$ \\
\hline 2016 & $2,527,057,547$ & $730,539,115$ & $789,|48,89|$ & $255,064,799$ & $992,308,480$ & $352,394,292$ & $5,646,513,124$ \\
\hline 2017 & $2,967,370,195$ & $594,507,472$ & $779,273,413$ & $410,351,080$ & $\mathrm{I}, 076,018,622$ & $389,553,384$ & $6,217,074,166$ \\
\hline 2018 & $4,496,036,022$ & $734,955,460$ & $\mathrm{I}, 063,434,223$ & $496,039,262$ & $|, 990,63|, 4 \mid 4$ & $417,988,889$ & $9,199,085,270$ \\
\hline Total & $22,92 \mathrm{I}, \mathrm{I} 36,026$ & $4,503,831,026$ & $4,241,573,650$ & $2,710,010,793$ & $7,328,135,604$ & $3,263,694,445$ & $44,968,38 I, 544$ \\
\hline
\end{tabular}

$13,301,840,842$ Yuan, and with an annual growth rate of $28.96 \%$. However, in the secondary expenditure projects, the average annual growth rate of expenditure in general hospitals, traditional Chinese medicine hospitals, other public hospitals, urban community health institutions, township health centers and other grass-roots medical and health institutions in the past decade were $11.44 \%$, $15.20 \%, 23.59 \%, 14.95 \%, 55.31 \%$ and $17.86 \%$, respectively. At the same time, the percentage of each project in the total expenditure of medical institutions was $50.97 \%, 10.02 \%, 9.43 \%, 6.03 \%, 16.30 \%$ and $7.26 \%$, respectively. Among them, the township hospitals had the highest average annual growth rate, with the total expenditure increased from 24,370,642 Yuan in 2009 to 1,990,631,414 Yuan in 2018; and the public hospitals accounted for the highest proportion, reaching 50.97\%, with a cumulative expenditure of 22,211,260,600 Yuan over 10 years.

However, in the field of public health expenditure, the total expenditure increased from 2,068,527,828 Yuan in 2009 to $3,906,135,308$ Yuan in 2018, with an average annual growth rate of $6.56 \%$.In the expenditure items of public health expenditure, disease prevention and control institutions, health supervision agency, maternity and child care institutions, emergency treatment institutions, blood collection and supply institutions, other professional public health institutions, the basic public health services and other public expenditure accounted for $13.87 \%, 4.15 \%$, $8.10 \%, 1.60 \%$, 5.62\%shi, 1.35\%, 29.81\%, 35.50\%, respectively. The average annual growth rates of various expenditures were $15.50 \%,-4.25 \%, 28.34 \%,-11.00 \%$, $-15.95 \%,-39.20 \%, 19.66 \%$, and $11.37 \%$. Among them, the maternal and child care institutions had the highest annual growth rate, and the expenditure of this project increased from 44,473,848 Yuan in 2009 to 539,366,541 Yuan in 2018.

\section{Government's Health Expenditure in the Four Prefectures of Southern Xinjiang}

Kashgar, Hotan, Aksu and Kizilsu Kirgiz Autonomous Prefecture are the four traditional Southern Xinjiang area in Xinjiang Uygur Autonomous Region, and also are the four most underdeveloped regions in Xinjiang. Thus, it was a great significance to analyze the health expenditure of the four prefectures in Southern Xinjiang. From Table 4, it could be seen that the health expenditure of the four areas in Southern Xinjiang increased from 807,957,961 Yuan in 2009 to 4,435,805,835 Yuan in 2018, with an annual growth rate of $18.57 \%$; the proportion of the government's health expenditure increased from $19.58 \%$ in 2009 to $33.85 \%$ in 2018 for the whole autonomous region. Among them, the average annual growth rate of health expenditure of Kashgar, Hotan, Aksu and Kizilsu Kirgiz Autonomous Prefecture, respectively, were $18.20 \%, 23.55 \%, 16.89 \%$ and $16.20 \%$, which were higher than the average annual growth rate of $12.25 \%$ in the whole autonomous region in the past decade. According to the census data in 2010, the total population of the four prefectures in Southern Xinjiang was $8,890,213$, accounting for $40.76 \%$ of the total population of the whole autonomous region $(21,813,334)$ at that 
Table 3 List of Public Health Expenditure of Xinjiang Uygur Autonomous Region Government from 2009 to 2018 (Yuan)

\begin{tabular}{|l|l|l|l|l|l|l|l|l|l|}
\hline & $\begin{array}{l}\text { Disease } \\
\text { Prevention } \\
\text { and Control } \\
\text { Agency }\end{array}$ & $\begin{array}{l}\text { Health } \\
\text { Supervision } \\
\text { Agency }\end{array}$ & $\begin{array}{l}\text { Maternal and } \\
\text { Child Health } \\
\text { Care } \\
\text { Institutions }\end{array}$ & $\begin{array}{l}\text { Emergency } \\
\text { Treatment } \\
\text { Institutions }\end{array}$ & $\begin{array}{l}\text { Blood } \\
\text { Transfusion } \\
\text { Services }\end{array}$ & $\begin{array}{l}\text { Other } \\
\text { Professional } \\
\text { Public } \\
\text { Health } \\
\text { Agencies }\end{array}$ & $\begin{array}{l}\text { Beasic Public } \\
\text { Health } \\
\text { Services }\end{array}$ & $\begin{array}{l}\text { Other } \\
\text { Public } \\
\text { Health } \\
\text { Agencies }\end{array}$ & $\begin{array}{l}\text { Total } \\
2009\end{array}$ \\
\hline 2010 & $186,508,079$ & $55,190,889$ & $85,920,544$ & $9,057,781$ & $20,524,497$ & $17,669,498$ & $312,956,263$ & $617,014,344$ & $1,299,841,897$ \\
2011 & $239,558,060$ & $200,508,996$ & $211,881,424$ & $131,472,550$ & $55,417,235$ & $110,865,485$ & $472,253,809$ & $1,049,971,938$ & $2,471,929,496$ \\
2012 & $282,844,757$ & $109,222,811$ & $95,182,114$ & $28,137,165$ & $97,963,322$ & $31,742,375$ & $471,725,465$ & $1,091,236,368$ & $2,208,054,378$ \\
2013 & $256,267,478$ & $68,682,142$ & $117,330,423$ & $58,171,093$ & $30,963,817$ & $8,752,936$ & $656,925,348$ & $637,341,052$ & $1,834,434,289$ \\
2014 & $337,871,233$ & $65,158,396$ & $122,322,057$ & $14,045,812$ & $30,066,169$ & 640,000 & $744,366,788$ & $619,596,467$ & $1,934,066,921$ \\
2015 & $326,695,857$ & $76,657,777$ & $240,317,427$ & $10,059,572$ & $36,493,146$ & $1,548,916$ & $940,201,651$ & $672,617,202$ & $2,304,591,547$ \\
2016 & $392,562,617$ & $82,166,109$ & $214,672,532$ & $24,517,482$ & $62,088,726$ & $1,589,695$ & $1,195,625,113$ & $1,127,479,173$ & $3,100,701,447$ \\
2017 & $564,905,886$ & $91,666,721$ & $345,642,859$ & $7,593,924$ & $78,047,698$ & 458,400 & $1,200,999,054$ & $1,479,931,853$ & $3,769,246,396$ \\
2018 & $704,061,303$ & $111,902,482$ & $539,366,541$ & $27,244,230$ & $147,904,316$ & $1,117,311$ & $1,223,342,187$ & $1,151,196,939$ & $3,906,135,308$ \\
Total & $3,452,971,746$ & $1,033,957,983$ & $2,017,109,769$ & $397,601,304$ & $1,399,777,07 \mid$ & $336,128,328$ & $7,421,607,360$ & $8,838,375,946$ & $24,897,529,507$ \\
\hline
\end{tabular}

Table 4 List of Public Health Expenditure of Four Prefectures in Southern Xinjiang from 2009 to 2018 (Yuan)

\begin{tabular}{|c|c|c|c|c|c|c|c|}
\hline & Hotan & Kashgar & Kizilsu Kirgiz & Aksu & Total & Whole Xinjiang & Ratio(\%) \\
\hline 2009 & $|23,029,2| \mid$ & $312,269,879$ & $73,584,138$ & $299,074,733$ & $807,957,961$ & $4,125,4 \mid 8,263$ & 19.58 \\
\hline 2010 & $205,231,569$ & $383,818,011$ & $61,970,142$ & $381,542,707$ & $1,032,562,428$ & $4,482,389,463$ & 23.04 \\
\hline 2011 & $301,88 I, 468$ & $591,459,389$ & $105,939,21 \mid$ & $517,663,569$ & $1,516,943,637$ & $5,906,529,018$ & 25.68 \\
\hline 2012 & $233,178,947$ & $492,102,815$ & $96,723,208$ & $409,890,574$ & $\mathrm{I}, 23 \mathrm{I}, 895,545$ & $5,524,416,907$ & 22.30 \\
\hline 2013 & $256,011,507$ & $5|8,96|, 575$ & $99,864,621$ & $500,838,204$ & $\mathrm{I}, 375,675,907$ & $5,074,812,024$ & 27.11 \\
\hline 2014 & $248,925,891$ & $543,393,306$ & $169,562,927$ & $492,776,594$ & $1,454,658,718$ & $5,766,518,689$ & 25.23 \\
\hline 2015 & $319,124,669$ & $606,785,024$ & $139,097,060$ & $735,794,913$ & $\mathrm{I}, 800,80 \mathrm{I}, 665$ & $7,147,070,976$ & 25.20 \\
\hline 2016 & $444,28 I, 767$ & $883,169,903$ & $140,298,757$ & $708,804,75$ I & $2,176,555,179$ & $8,747,2|4,57|$ & 24.88 \\
\hline 2017 & $494,693,367$ & $793,599,421$ & $209,759,768$ & $\mathrm{I}, 017,972,346$ & $2,516,024,901$ & $9,986,320,562$ & 25.19 \\
\hline 2018 & $1,019,649,367$ & $1,662,155,469$ & $330,305,593$ & $\mathrm{I}, 423,695,406$ & $4,435,805,835$ & $13,105,220,578$ & 33.85 \\
\hline Total & $3,646,007,764$ & $6,787,7 \mid 4,793$ & $\mathrm{I}, 427,105,424$ & $6,488,053,795$ & $|8,348,88|, 776$ & $69,865,9|1,05|$ & - \\
\hline
\end{tabular}

time, which was far higher than the proportion of medical and health expenditure $\left(\chi^{2}=7.445, \mathrm{P}=0.006\right)$.It showed that the government's health expenditure in the four prefectures of Southern Xinjiang still needed to be strengthened, though Aksu and Kizilsu Kirgiz Autonomous Prefecture due to their small population, has reached the average level of Xinjiang Uygur Autonomous Region (Figure 3).

\section{Discussion}

\section{The Shortage of Autonomous Region Government's Overall Financial Expenditure on Health Expenditure Remains to Be Further Strengthened}

During the first 10 years since Chinese new medical reform, although the health expenditure of the all levels governments in the autonomous region has been increasing, and the proportion of this expenditure in the GDP of the whole region has also been increasing (that have reached $1.07 \%$ ), the annual average growth rate has also reached $12.25 \%$, which was higher than the annual growth rate of $11.06 \%$ of the total GDP in the same period, compared with the overall level of the country, there was still a certain gap. Guo Feng ${ }^{7}$ reported that since the 18th National Congress of the Communist Party of China, the annual growth rate of Chinese government's health expenditure has been $12.52 \%$, so the expenditure growth rate in Xinjiang was similar to that of the whole country. The national government's health expenditure has reached $1.70 \%$ of the total GDP of 2018 , while the proportion in Xinjiang had only reached $1.07 \%$ in 2018 , which was far below the national average level. So there was plenty of fiscal space for health to increase. The WHO offered seven options to increase in fiscal space for health, including 
reprioritizing expenditure, Raising revenue, boosting efficiency, increasing borrowing, securing more external grants, monetary expansion and conducive overall macroeconomic conditions in $2017 .^{8}$ Xinjiang as a remote economically underdeveloped area only could increase in fiscal space for health by reprioritizing health expenditure and securing more external grants from the advanced regions of China.

Meanwhile, the government per capita expenditure on health in the whole of China and the western region has reached 1093.88 Yuan and 1139.53 Yuan, respectively, in 2017, while that in Xinjiang only reached 526.95 Yuan in 2018, less than half of the national level. Compared with Inner Mongolia Autonomous Region, the proportion of government health expenditure in Xinjiang was still less. According to Wenlan reported, ${ }^{9}$ the government health expenditure in Inner Mongolia accounted for $1.36 \%$ of the total GDP in 2014, and $6.27 \%$ of the local financial expenditure, which both were higher than those in Xinjiang. However, compared with the Inner Mongolia Autonomous Region, the per capita government health expenditure was not much different, less than $50 \%$ of the national average.

Therefore, in terms of the situation of the whole country and other provinces, the government's health expenditure in Xinjiang Uygur Autonomous Region still had a large space to increase. ${ }^{10,11}$ In addition, from the perspective of realizing the 13th five-year plan of health development and building a well-off society in an allround way in 2020 , this paper examined the current situation of government health expenditure in Xinjiang, the government health expenditure was also an urgent work. Thus, it was still necessary for governments at all levels in Xinjiang to continue to increase the intensity of government health expenditure, and to effectively guarantee the increasing intensity of government health expenditure through laws and regulations, then they could strive to reach the overall level of the country as soon as possible.

\section{The Structure of Government Expenditure on Health Needs to Be Improved}

During the 10 years of the new medical reform, the government's financial expenditure in medical institutions and public health agencies has changed significantly. Because it benefited from the new model of medical reform, the proportion of government financial expenditure in medical institutions has been continuously strengthened, which have been accounted for $70.22 \%$ of the total government expenditure in 2018. And the average annual growth rate was also as high as $16.16 \%$ during the 10 years, far higher than the average annual growth rate of $5.65 \%$ in the field of public health. These data indicated that the universal health insurance model plays an important role in the government's health care expenditure. However, the proportion of medical institutions in Xinjiang compared to the national level was relatively high, the overall national level was about $45 \%$, which was far lower than the level of $70.22 \%$ in Xinjiang. The primary reason was that there was a large number of farmers and herdsmen in Xinjiang, whose medical insurance reimbursement ratio was much higher than that of the general population. Secondly, a series of medical insurance reimbursement policies for the elderly issued by the Autonomous Region Government have improved the reimbursement ratio of the elderly. Finally, because of the relatively backward medical and health conditions, the prevalence of major diseases and chronic diseases in Xinjiang was higher than the national level, thus leading to a heavier burden on health care. All of these reasons lead to the government health expenditure concentrate on major hospitals, thereby reducing the government financial expenditure in public health. ${ }^{12}$ Because the government public health expenditure has been compressed, many diseases could not be effective in preventing, which leads to the incidence of various major diseases and chronic diseases can not effectively reduce, and thus forming a vicious cycle. That was to say, because the proportion of government public health expenditure was reduced, it could not do better in disease prevention, and could not effectively enhance the concept of universal health. This was why the incidence of various diseases is so high. The more money needed for personal health care, the more the government will invest in personal health care, which leads to a further squeeze on public health funds. In order to break up this vicious circle, a reasonable plan of government health expenditure must be established, balance the proportion of medical institutions and public health expenditure, and appropriately increase the annual growth rate of public health expenditure, so as to reach a reasonable proportion of expenditure as soon as possible.

In the past 10 years, the total expenditure of public hospitals was 2.38 times of primary medical and health institutions, which showed that it was still a long way to implement Premier Li Keqiang's important instructions on 
strengthening the primary level of medical reform in Xinjiang Uygur Autonomous Region. However, it was gratifying that in the past decade, the annual growth rate of expenditure in primary medical institutions has been as high as $28.96 \%$, far higher than the average annual growth rate of $13.16 \%$ in public hospitals, which made us believe that in the fact the expenditure in primary medical institutions will surpass public hospitals in the future. By analyzing the input data of grass-roots medical institutions, it also was found that the expenditure of township health centers has been continuously strengthened. In the past decade, the financial expenditure of township health centers was 2.70 times than urban community health institutions, and the annual growth rate was as high as $55.31 \%$, far higher than the $14.95 \%$ annual growth rate of urban community health institutions, it showed that the government finance of Xinjiang Uygur Autonomous Region has paid more attention to rural medical institutions. The support of health care, especially township hospitals, is in line with the policy that the new medical reform of the country inclines to the medical and health expenditure in rural areas.

\section{The Health Expenditure of Four Prefecture in Southern Xinjiang Has a Long Way to Go}

The government expenditure on medical and health care in the undeveloped and remote areas has always been a difficult problem. ${ }^{13}$ The four prefectures in Southern Xinjiang are the areas with backward economy, poor health conditions and a large proportion of minority population in Xinjiang. The status of medical and health level in this area plays a role of cask effect on the overall medical and health level in Xinjiang to some extent. Through the analysis, it could be found that, although the annual growth rate of the government's medical and health expenditure in the four southern regions was as high as $18.57 \%$, which was higher than the overall annual growth rate of $12.25 \%$ in Xinjiang, but because the baseline level before the medical reform was too low, the current level of the government's medical and health expenditure in Kashgar and Hotan was still far lower than the level of the whole autonomous region, even very far from the national average level. The main reason for this phenomenon is that the economic level of Southern Xinjiang prefectures is too backward, and the financial revenue of the local government was limited. The funds invested in the local areas mainly came from the transfer of financial funds from the central government and the autonomous region, as well as financial assistance from some provinces and cities of the Chinese developed area. How to solve this problem is mainly to obtain more input subsidies from the central finance and the autonomous region's finance for local medical and health care through multiple channels, so as to increase the level of local medical and health expenditure, improve the local medical and health conditions, and realize the grand blueprint of all the people in Xinjiang Autonomous Region to enter the well-off society in 2020 .

\section{Conclusion}

In the first decade of the new medical reform, restricted by the regional economic conditions and social reality, the financial expenditure of Xinjiang Uygur Autonomous Region government to medical and health care was generally less, especially in the four prefectures of Southern Xinjiang such as Kashgar and Hotan, at the same time, the expenditure of medical institutions and public health is unbalanced. So the governments at all levels of the autonomous region should continuously strengthen the financial expenditure in medical and health care, maintain the current situation of better implementation of the policy for inclining to rural and grass-roots expenditure, constantly optimize the proportion of various financial expenditures. Strive to achieve the general goal of social stability, longterm stability and stability in Xinjiang Uygur Autonomous Region, and strive for all ethnic people in Xinjiang to enter a well-off society in an all-round way.

\section{Funding}

The study was funded by the National Natural Science Foundation of China (No.71662033).

\section{Disclosure}

The authors declare that they have no competing interests.

\section{References}

1. Li JJ, Huang YR, Nicholas S, et al. China's new cooperative medical scheme's impact on the medical expenses of elderly rural migrants. Int J Environ Res Public Health. 2019;16(24):4953. doi:10.3390/ ijerph16244953

2. Tao WJ, Zeng Z, Dang HX, et al. Towards universal health coverage: lessons from 10 years of healthcare reform in China. BMJ Glob Health. 2020;5(3):e002086. doi:10.1136/bmjgh-2019-002086

3. Lijie F. Understanding the dilemma of "new medical reform": review of "12th five year plan" medical reform. J State Admin Coll. 2016;2:77-81. 
4. Ling L. Review on the progress of new medical reform. China Health Econ. 2012;31(1):5-9.

5. Qian Q. Research on the current situation and Countermeasures of China's financial and health expenditure. Financial Inf. 2018;13:45.

6. Lin W, Lan W, Shuling Z, et al. Study on the government responsibility of public investment in health care: a case study of Tianjin. China Health Econ. 2011;30(10):18-20.

7. Feng G, Yuhui Z, Quan W, et al. Analysis of government health input since the 18th CPC National Congress. China Health Econ. 2019;38 (04):9-12.

8. World Health Organization. UHC Technical brief: Fiscal space for health; 2017. Available from: https://apps.who.int/iris/bitstream/handle/10665/ 258893 /fiscal_space_for_health.pdf? sequence $=1 \&$ isAllowed $=y$ Accessed April 62020.
9. Lan W, Jing S, Yancun F, et al. Analysis of government health investment in Inner Mongolia Autonomous Region since the new medical reform. China Health Econ. 2017;36(05):44-47.

10. Chunping L, Mingyang Y, Xiaoping L, et al. Analysis of health input of Hainan provincial government. China Health Econ. 2014;33(11):76-78.

11. Chunli Z, Zhen Z. Research on health expenditure of Zhejiang provincial government since the new medical reform. Health Econ Res. 2015;(06):12-15.

12. Bin Y, Xiaojun Z. Xinjiang medical insurance: adapting to the new normal of economy and supported by big data. China Soc Sec. 2017;07:79-81.

13. Jianhua G. Research on the current situation and Countermeasures of public finance medical and health investment in remote mountainous areas: a case study of Western Guangxi. $J$ Youjiang Univ Nationalities Med. 2013;35(3):352-354.
Risk Management and Healthcare Policy

\section{Publish your work in this journal}

Risk Management and Healthcare Policy is an international, peerreviewed, open access journal focusing on all aspects of public health, policy, and preventative measures to promote good health and improve morbidity and mortality in the population. The journal welcomes submitted papers covering original research, basic science, clinical \& epidemiological studies, reviews and evaluations,

\section{Dovepress}

guidelines, expert opinion and commentary, case reports and extended reports. The manuscript management system is completely online and includes a very quick and fair peer-review system, which is all easy to use. Visit http://www.dovepress.com/testimonials.php to read real quotes from published authors. 